\title{
EMPRESA HUMANIZADA: a organização necessária e possível
}

\author{
Sylvia Constant Vergara \\ Mestre em Administração pela FGV-EBAP, Doutora em Educação pela UFRJ, \\ Coordenadora de cursos de Educação Continuada da FGV (RJ) e Professora da FGV-EBAP. \\ E-mail:vergara@fgv.br \\ Paulo Durval Branco \\ Mestre em Administração pela PUC (RJ), Professor da PUC (RJ) e FGV (RJ), \\ Diretor da AMCE Negócios Sustentáveis e Consultor da Vision Desenvolvimento de Pessoas.
} E-mail:pbranco@amce.com.br

RESUMO

0 presente artigo discute algumas das questões referentes à humanização das empresas e justifica a premência e a possibilidade de sua viabilização. Entende por empresa humanizada aquela que, voltada para seus funcionários e/ou para 0 ambiente, agrega outros valores que não somente a maximização do retorno para os acionistas. Nesse sentido, são mencionadas empresas que, no âmbito interno, promovem a melhoria na qualidade de vida e de trabalho, visando à construção de relações mais democráticas e justas, mitigam as desigualdades e diferenças de raça, sexo ou credo, além de contribuírem para o desenvolvimento e crescimento das pessoas. Ao focalizar o ambiente, as ações dessas empresas buscam a eliminação de desequilíbrios ecológicos, a superação de injustiças sociais, o apoio a atividades comunitárias, enfim, o que se convencionou chamar de exercício da cidadania corporativa.

\section{ABSTRACT}

The article discusses some questions about the humanization of companies and justifies its urgency and feasibility. It's understood that the humanized company is one that, focused on its employees and/or on the external environment, links other values besides maximizing the return for the stockholders. Continuing on this line are mentioned companies that, in the internal environment, promote an enhancement in quality of life and of work, concentrating on the construction of more democratic and just relationship, reducing inequality and racial, gender and belief prejudice, besides contributing to the development and growth of people. Focusing on the environment, the actions taken by these companies are directed towards the elimination of ecological unbalance, overcoming social injustice, community support and towards everything that is called corporate citizenship.

\section{PALAVRAS-CHAVE}

Organizações humanizadas, cidadania corporativa, responsabilidade social, empresa e sociedade, sustentabilidade corporativa.

KEY WORDS

Humanized organization, corporate citizenship, social responsibility, organizations and society, corporate sustainability. 


\section{INTRODUÇÃO}

Se hoje é um dia típico em nosso planeta, semelhante aos que se têm sucedido ao longo dos últimos anos, alguns fatos estão-se consolidando como uma rotina. Pela sua repetição, já não parecem causar alarme a muitos. Na verdade, passam a ser encarados com normalidade. Destacar alguns deles pode ser esclarecedor.

Como parte dessa rotina, ao final do dia de hoje, deixaremos de contar com cerca de 100 espécies animais e vegetais, muitas das quais sequer chegamos a conhecer, o que representa um ritmo 50 a 100 vezes maior do que o observado em condições normais de equilíbrio natural (ONU, 1998). Nossa atmosfera terá recebido algo em torno de 2,7 mil toneladas de clorofluorcarbono (CFC) e 15 milhões de toneladas de dióxido de carbono $\left(\mathrm{CO}_{2}\right)$, gases relacionados, respectivamente, ao aumento do buraco na camada de ozônio e ao aquecimento do planeta. Passaremos a contar com mais 250 mil habitantes, num planeta que perde 450 $\mathrm{m}^{2}$ de floresta tropical por segundo (Orr, 1994). Ao cair da noite de hoje, teremos um planeta mais quente, com águas mais ácidas, ar menos saudável e menor quantidade de terras adequadas ao plantio.

Habitando a Terra e contribuindo com os dados que consolidam essa rotina, uma população mundial de cerca de 6 bilhões de pessoas conta com 1,2 bilhão vivendo em condições de pobreza absoluta, conforme constata o último Relatório de Desenvolvimento Humano da Organização das Nações Unidas (ONU, 2000). Já os que se situam acima da linha de pobreza, colaboram para alimentar taxas de consumo que vêm crescendo significativamente ao longo das últimas décadas, tendo dobrado de 1975 para 1998 e crescido seis vezes quando comparadas a 1950 . Se o crescimento do consumo e a sua diversidade aumentam num ritmo vertiginoso, o mesmo não pode ser observado com relação à sua distribuição. Enquanto $20 \%$ dos habitantes dos países mais ricos são responsáveis por $86 \%$ do total do consumo mundial, os $20 \%$ dos mais pobres consomem $1,3 \%$ desse total. Se não bastasse o desequilíbrio dessa distribuição, é preciso lembrar que o padrão de consumo dominante insiste em considerar os recursos naturais como infinitos, o que leva ao esgotamento de muitos deles, por exemplo, água e solo, e à insustentabilidade desse tipo de relação com a natureza.

Ao que parece, não é só o padrão de consumo daqueles que podem consumir que se está demonstrando insustentável. Também o é um sistema econômico que não leva em conta as pessoas (Forrester, 1997; Schumacher, 1983), uma ciência desprovida de va- lores (Capra, 1982; Morin, 1996), uma educação que massifica e aliena (Freire, 1974; Hern, 1996), uma administração que não permite a plena realização do potencial humano nas empresas (Aktouf, 1996; Chanlat, 1990), assim como tantas outras criações humanas fundamentadas em premissas que precisam ser revistas

A urgência na superação dessas questões não mais permite a procura por culpados ou a escolha de bodes expiatórios para erros e omissões. Enquanto se discute a quem cabe solucionar as disfunções do modelo de desenvolvimento adotado, só se está contribuindo para o agravamento dos desequilíbrios e desigualdades de uma época marcada por profundas insatisfações. É preciso agir para minorá-las. Nesse sentido, cabe indagar o papel que as empresas têm a desempenhar.

\section{Ao cair da noite de hoje,}

\section{teremos um planeta mais}

quente, com águas mais

ácidas, ar menos saudável

e menor quantidade de

terras adequadas ao plantio.

Por que é importante questionar o papel da empresa nesse contexto, se ela é apenas mais uma das tantas instituições que estão definindo os contornos neste início de século? Se entendemos as empresas como construções sociais, sujeito e objeto da realidade da qual fazem parte, não é difícil identificar sua participação tanto no agravamento quanto na superação dos múltiplos problemas até aqui mencionados. Seja pelo poder econômico que possuem, seja pelo conjunto de competências técnicas de que dispõem, as empresas são hoje uma das instituições mais influentes nos rumos da sociedade. Como argumenta Harman (1996), a empresa moderna, que sobrevive em um ambiente de constantes mudanças, é hoje uma das instituições mais adaptáveis, se comparada a outras como as igrejas e os governos, o que lhe confere um papel de liderança nas transformações necessárias.

O presente artigo pretende discutir algumas das questões referentes à humanização das empresas e justificar a premência e a possibilidade de sua viabilização. Entende por empresa humanizada aquela que, voltada para seus funcionários e/ou para o ambiente, agre- 
ga outros valores que não somente a maximização do retorno para os acionistas. Realiza ações que, no âmbito interno, promovem a melhoria na qualidade de vida e de trabalho, visam à construção de relações mais democráticas e justas, mitigam as desigualdades e diferenças de raça, sexo ou credo, além de contribuírem para o desenvolvimento das pessoas sob os aspectos físico, emocional, intelectual e espiritual. Ao focalizar o ambiente, essas ações buscam a eliminação de desequilíbrios ecológicos, a superação de injustiças sociais, o apoio a atividades comunitárias, enfim, o que se convencionou chamar de exercício da cidadania corporativa.

O artigo está estruturado em seis seções, além desta introdução. A primeira apresenta informações que, por si só, justificam o tema deste artigo; focaliza a empresa e a sociedade. A segunda explicita os contrastes que ora vivemos com grande intensidade. Na terceira seção, discutimos a natureza do que hoje é interpretado como crise das sociedades, os pressupostos nos quais se baseia e as possibilidades que se abrem para a sua superação. A quarta aponta a necessidade de reconciliar competição e cooperação. Na quinta seção, são apresentados alguns exemplos de empresas que já estão viabilizando o caráter humanista que as norteia. A sexta apresenta as conclusões a que o estudo permitiu chegar.

\section{EMPRESA E SOCIEDADE}

O século XX foi palco de desafios sucessivos para as empresas. Na primeira metade desse período, a existência de uma demanda crescente, num mercado menos competitivo, teve como resposta a ênfase na maximização dos processos produtivos e na manutenção de estruturas e procedimentos que tinham no controle sua razão de existir. À medida que, após a virada do século, os consumidores começaram a se mostrar mais exigentes e os competidores mais numerosos e eficientes, às melhorias nas atividades produtivas foi preciso adicionar maior orientação para o mercado. $\mathrm{O}$ marketing assumiu lugar de destaque, defendendo a idéia de que o cliente deveria ser o foco. As empresas que melhor aprendiam essa lição obtinham resultados, mas passavam a perceber que, em intervalos de tempo cada vez menores, o que era fonte de diferenciação logo se tornava pré-requisito.

Por trás das tentativas de superar os desafios que se apresentam, a busca pela sobrevivência, por parte das empresas, vem-se mostrando uma motivação básica e, em geral, desarticulada de considerações sobre outros agentes e recursos que devem continuar existindo para que essa sobrevivência seja possível. Competentes em responder às ameaças intrínsecas ao seu ambiente operacional, no que diz respeito à produção e à comercialização de bens e serviços, as empresas têm-se mostrado negligentes quanto aos fatores que dão sustentação a esse mesmo ambiente. Historicamente, essa negligência tem-se revelado pelas inexpressivas conquistas em termos de qualidade de vida da maioria dos trabalhadores, pela exploração irresponsável dos recursos naturais, pelo descompromisso com qualquer grupo de interesse que não seja o dos acionistas.

Diante das características deste início de século, marcado por desigualdades e desequilíbrios complexos e interdependentes, torna-se cada vez mais evidente a insustentabilidade das práticas comerciais que só contemplem a maximização do retorno sobre o capital. Mais uma vez expostas a um desafio sem precedentes, as empresas terão de provar que as competências e recursos que conquistaram, muitas vezes em detrimento das necessidades da sociedade que as acolhe, podem contribuir para um modelo de desenvolvimento efetivamente sustentável.

Ações conducentes a tal desenvolvimento nem sempre fizeram parte da agenda de empresários e executivos, considerados insensíveis às desigualdades e às carências sociais. Muito pelo contrário. Como certa vez comentou a cineasta Tizuka Yamasaki, a maneira mais fácil de se caracterizar um vilão em um filme era associá-lo à figura de um empresário. Mas parece que essa imagem pode estar com os dias contados. É crescente o número de representantes do meio empresarial que afirma "que um comportamento socialmente responsável é o fundamento de um sucesso econômico sustentável a longo prazo" (Leal, 1998, p. 142).

Ao mesmo tempo em que a humanização empresarial ganha adeptos que buscam potencializar suas ações por meio de instituições como a Business for Social Responsibility, a Social Venture Network, a World Business Academy, todas norte-americanas, a européia Prince of Wales's Business Leaders Forum e o recémcriado Instituto Ethos no Brasil, argumenta-se que esse movimento é um dos indícios de uma mudança ainda mais profunda que estaria em curso no mundo dos negócios. Nas palavras de Michael Ray, professor da Stanford University, essa mudança poderia ser entendida como a emergência de um novo paradigma nos negócios (Ray, 1997). Ao fazer essa afirmação, o autor utiliza-se do sentido que Kuhn (1982) atribui à expressão "mudança de paradigma" na ciência, ou seja, a situação em que os pressupostos até então aceitos, assim como o conjunto de teorias desenvolvido, dão sinais de incapacidade no que se refere à explicação da realidade, rica em contrastes. Estar-se-ia vivendo esse momento nos negócios? Para muitos autores, sim. 


\section{DESENVOLVIMENTO E INSATISFAÇÃO: FACES DE UMA ERA DE CONTRASTES}

Ao discutir a aceleração do processo de mudança que estamos vivendo, Toffler (1981) propõe uma divisão dos últimos 50 mil anos da História da humanidade em períodos de 62 anos cada um, o que equivale ao tempo médio de uma geração. Essa divisão resultaria em cerca de 800 períodos, dos quais:

- 650 foram vividos nas cavernas;

- 70 tiveram o uso da escrita;

- 6 foram marcados pela palavra impressa;

- os últimos 4 viram a medição mais precisa do tempo;

- os 2 últimos tiveram o uso de motores elétricos;

- o atual, ou seja, o $800^{\circ}$ foi palco da maioria dos conhecimentos e bens materiais que hoje são utilizados.

Se se observam os recentes avanços tecnológicos, não há nenhum sinal de redução desse ritmo. Ao contrário, a obsolescência de conhecimentos de base científica ocorre em períodos cada vez menores. Machado (1997) estima que, a cada dois ou três anos, o acervo de conhecimento disponível dobre. Ao mesmo tempo em que isso se verifica, outros aspectos manifestamse. No que se refere à distribuição de riquezas geradas pelo modelo de desenvolvimento dominante, os sucessivos alertas emitidos pela ONU e outras instituições dedicadas ao estudo das condições de vida humana apontam para um enorme desequilíbrio. Nesse sentido, mostra-se representativa a concessão do Prêmio Nobel de Economia de 1998 a um pesquisador envolvido com temas relativos à distribuição de riqueza. Economista de origem indiana, o professor Amartya Sen dedica-se ao estudo da economia do bem-estar social, buscando ampliar a compreensão dos mecanismos econômicos subjacentes à fome. Nas palavras do presidente da Índia, K. R. Narayanan, o trabalho do professor Sen "trouxe para a ciência da economia uma compaixão pelo ser humano comum e a visão de uma sociedade mundial igualitária" (Lynn, 1998, p. A-12).

Além do descompasso entre a geração e a distribuição de riquezas produzidas no mundo, convivemos com um elevado desenvolvimento tecnológico e um baixo desenvolvimento pessoal e interpessoal. Ao mesmo tempo em que se é capaz de viajar para os planetas vizinhos, fazer prospecção em águas profundas, mergulhar no universo microscópico dos átomos, criar computadores que cabem na palma da mão, oferecer produtos tailor made, desenvolver a engenharia genética em níveis inimagináveis, pouco se conhece sobre si mesmo e sobre os outros, mostrando-se, a todo o tempo, a incapacidade de lidar com diferenças individuais.
Semelhantemente ao que ocorre entre o desenvolvimento tecnológico e o pessoal e interpessoal, também é notório o descompasso que caracteriza as relações do ser humano com o ambiente natural. Na ânsia pelo crescimento econômico e pelo atendimento à demanda gerada por incessantes estímulos ao

\section{A empresa moderna, que}

\section{sobrevive em um ambiente de}

constantes mudanças, é hoje

uma das instituições mais

adaptáveis, se comparada a

outras como as igrejas e os

governos, o que lhe confere

um papel de liderança nas

transformações necessárias.

consumismo, tem-se esquecido que vivemos em um ecossistema finito, onde a inconseqüência no lançamento de rejeitos e na extração de recursos naturais não tarda a se converter em condições de vida impróprias. Conforme aponta o Relatório de Desenvolvimento $\mathrm{Hu}-$ mano da ONU (1998), um sexto do total de terras cultiváveis do planeta encontra-se degradado devido ao uso excessivo e às práticas inadequadas de cultivo. Da mesma forma, é expressivo o declínio do estoque de peixes nos oceanos, pois um quarto está em via de extinção, enquanto $44 \%$ do restante vem sendo pescado no seu limite biológico, sendo a extração mais acelerada do que a reposição. Se considerado o caso do bacalhau na costa do Canadá, podemos constatar que a drástica redução no número de exemplares de uma espécie significa, para a teia da vida, não apenas uma ruptura biológica mas também social e econômica, como revelado pelos 40 mil empregos que deixarão de existir nas atividades ligadas à pesca do bacalhau naquele país (Ryland, 1998).

A maneira pela qual se tem lidado com a natureza fundamenta-se na visão mecanicista atual do mundo, no orgulho que tal visão proporciona em dominar e controlar a natureza. Não é uma maneira apropriada. A relação deveria ser de respeito, de diálogo. Talvez se devesse resgatar a atitude batesoniana de observar, com empatia e paixão, uma planta ou um animal e de 
descrevê-los detalhadamente, com amor (Capra, 1997). Talvez se devesse recuperar um tanto da visão romântica que Goethe tinha da natureza, bem como da imagem mítica de Gaia, a Deusa Terra cultuada na Grécia antiga (Capra, 1997). Como ensina Lynn Margulis (citado por Capra, 1997, p. 94), "quando os cientistas nos dizem que a vida se adapta a um meio ambiente essencialmente passivo de química, física e rochas, eles perpetuam uma visão seriamente distorcida". Gaia é a terra viva. A teoria de Gaia, desenvolvida por Lynn Margulis e James Lovelock, considera a vida de maneira sistêmica, percebendo suas inter-relações.

Associando-se questões como distribuição de renda, consumo e degradação ambiental, também é ilustrativa a constatação do referido relatório da $\mathrm{ONU}$ (1998), segundo a qual uma pessoa nascida em um país industrializado representa um impacto em termos de consumo e poluição, ao longo de sua vida, 30 a 40 vezes maior do que o de uma pessoa nascida em um país em desenvolvimento.

Muitas têm sido as conquistas realizadas pelos avanços tecnológicos implementados pelo homem. Doenças endêmicas têm sido erradicadas, distâncias têm sido eliminadas pelos avanços das telecomunicações, o universo vem sendo explorado em viagens interplanetárias, entre outras conquistas. Entretanto, essas realizações não acontecem sem custos, os quais se têm mostrado extremamente elevados, a ponto de provocar reflexões nos mais diversos segmentos da sociedade.

O modelo de desenvolvimento que alimentou todas essas conquistas sempre se baseou em uma mentalidade instrumental-tecnológico-consumista, a qual tem sido fonte de situações de colapso em várias áreas. A grave crise ambiental que hoje afeta o planeta é uma das conseqüências desse modelo multiplicado em escala e que, via de regra, serve de inspiração para as chamadas nações em desenvolvimento. Não é difícil imaginar os impactos da universalização de tal estilo de desenvolvimento. Basta lembrar que 20\% dos habitantes dos países mais ricos são responsáveis por $53 \%$ das emissões de dióxido de carbono $\left(\mathrm{CO}_{2}\right)$, enquanto os $20 \%$ dos mais pobres, por 3\% desse total (ONU, 1998).

O confronto dos inúmeros avanços científicos e tecnológicos com os desequilíbrios e desigualdades que persistem ao longo das últimas décadas torna inadiável a busca das raízes de tal descompasso como condição para sua possível superação.

\section{A NATUREZA DA CRISE E AS POSSIBILIDADES DE SUPERAÇÃO}

Ao desenvolver a teoria das estruturas dissipativas e ao afirmar o fim das certezas, Ilya Prigogine (1996) utiliza a metáfora do "efeito borboleta". Segundo ela, o batimento da asa de uma borboleta em Pequim pode provocar um leve sopro que, avançando gradativamente, vai dar nascimento a um furacão na Califórnia (citado por Sorman, 1989). A metáfora usada por Prigogine, baseada nas descobertas do meteorologista Edward Lorenz, segundo o qual um simples conjunto de equações não-lineares pode gerar um comportamento extremamente complexo (Capra, 1997), remete-nos à noção de interdependência entre os fenômenos, ou seja, mais do que realidades isoladas e auto-referenciadas, todos os fenômenos revelam os mútuos relacionamentos das partes que os compõem e os relacionamentos com o todo.

Compreender um fenômeno baseado na interdependência das partes que o compõem e na sua interdependência com o todo pode parecer um procedimento óbvio e a escolha natural em nossa apreensão da realidade. Entretanto, não é essa a visão tradicionalmente utilizada. Ao contrário, somos freqüentemente iludidos pela fragmentação e pelo reducionismo, os quais acenam com a possibilidade de controle e dominação das partes de um todo. A opção pelas partes encontra suas origens nas concepções baseadas na teoria matemática de Isaac Newton, na filosofia de René Descartes, na metodologia científica defendida por Francis Bacon, as quais se traduzem no alicerce da Física clássica. Conforme o entendimento desses pensadores, fenômenos complexos poderiam ser compreendidos desde que fossem reduzidos aos seus componentes básicos e investigados os mecanismos pelos quais tais componentes interagem. Conhecida como reducionismo, essa concepção encontra-se tão vinculada à nossa cultura que chega a ser identificada como sendo o próprio método científico.

A visão reducionista está, pois, associada às origens da Ciência moderna, possuindo estreita ligação com o pensamento filosófico orientado pelo dualismo espírito/matéria que veio à tona no século XVII com René Descartes. Descartes via a natureza como derivada de uma divisão entre dois reinos independentes: o da mente e o da matéria. A chamada divisão "cartesiana" levou ao tratamento do objeto como algo separado do observador, legitimando uma visão do mundo como uma máquina de enormes proporções em que tudo poderia ser previsto e, sobretudo, controlado. Na interpretação de Capra, a filosofia de Descartes, em vez de levar o homem ocidental a igualar sua identidade a todo o seu organismo, conduziu-o a igualá-la apenas à sua mente (Capra, 1975).

A concepção cartesiana do mundo tem sido ostensivamente associada à dificuldade que se tem em apreender a realidade segundo sua verdadeira natureza: uma teia de fenômenos interconectados (Bohm, 1992; Capra, 
1982, 1997; Maturama e Varela, 1972; Prigogine e Stengers, 1984; Morin, 1996; Wilber, 1977, 1991). Resulta daí a incapacidade de serem explicadas inúmeras das transformações que se processam no mundo, segundo os modelos herdados da visão reducionista e fragmentada. Essa incapacidade está associada ao conceito de anomalia mencionado por Thomas Kuhn (1982) ao tratar da noção de paradigma. A anomalia ocorre, segundo Kuhn, quando os experimentos e as pesquisas produzem resultados que não são explicados pela teorias pertinentes. A incompatibilidade entre os resultados e o que havia sido previsto pela teoria é a anomalia.

Do grego, "padrão", e inicialmente utilizado no campo da epistemologia, o termo paradigma tem sido apropriado por inúmeras áreas do conhecimento. Se, em algumas ocasiões, é empregado com lucidez, em outras, revela equívocos evidentes, sendo muitas vezes invocado como fonte de credibilidade e de adequação aos modismos intelectuais vigentes. Conforme observado por Thomas Kuhn, existe um conjunto de teorias e pressupostos conceituais, metodológicos e metafísicos sobre o qual a Ciência se apóia e que lhe serve de modelo ou padrão; serve-lhe de paradigma. Os paradigmas estão associados, portanto, às "realizações científicas universalmente reconhecidas que, durante algum tempo, fornecem problemas e soluções modelares para uma comunidade de praticantes de uma ciência" (Kuhn, 1982, p. 13).

Considerando-se um conjunto de evidências que surgem em diferentes áreas do conhecimento, podemos constatar a possibilidade de estar tomando forma, segundo a concepção de Kuhn (1982), uma mudança paradigmática.

No campo da Física, a inadequação do paradigma até então disponível, de base newtoniana-cartesiana, já começou a se revelar nas primeiras décadas do século XX, quando pesquisadores como Albert Einstein, Neils Bohr, Werner Heisenberg e outros revelaram as limitações de se considerar um universo determinístico e passaram a apontar para a necessidade de aceitação da incerteza dentro de uma realidade probabilística. Nem mesmo a convicção para afirmar que um elemento era matéria ou radiação permaneceu, já que dentro de certas condições poderia ser tratado como partícula ou como onda. É oportuno lembrar que o Prêmio Nobel de Física, em 1906, foi concedido ao cientista J. J. Thomson, que demonstrou que os elétrons eram partículas. Já em 1937, o mesmo prêmio foi recebido pelo filho de Thomson, George Thomson, que demonstrou serem os elétrons ondas. Como hoje se sabe, ambos tinham razão (Cohen, 1998).

Se com a consolidação da Física moderna, por meio dos estudos das partículas atômicas e subatômicas, fi- caram evidentes as limitações do antigo paradigma, também têm sido freqüentes as contribuições surgidas em outras áreas do conhecimento que apontam para uma nova visão de mundo. Na Química, na Biologia, nas Neurociências, na Psicologia, na Cibernética, na Antropologia, na Matemática da complexidade ou em outros campos do saber humano, essa nova visão, que sem

\section{$\mathrm{Na}$ ânsia pelo crescimento}

\section{econômico e pelo atendimento à} demanda gerada por incessantes estímulos ao consumismo, tem-se esquecido que vivemos em um ecossistema finito, onde a inconseqüência no lançamento de rejeitos e na extração de recursos naturais não tarda a se converter em condições de vida impróprias.

muita precipitação poderia ser chamada de um paradigma emergente, revela, no dizer de Capra (1997), "a teia da vida". Ela trata:

a) da abordagem holística que, diferentemente da reducionista, propõe que as partes sejam tratadas segundo seus mútuos relacionamentos e o relacionamento com o todo;

b) da impossibilidade de aceitar-se que propriedades "objetivas" da natureza sejam independentes de quem as observa;

c) da construção do homem pela sociedade e, dialeticamente, da construção da sociedade pelo homem;

d) do homem segundo uma perspectiva integrada, um todo de natureza física, emocional, intelectual e espiritual. Não aceita, portanto, dicotomias do tipo mente/corpo ou espírito/matéria;

e) da valorização do ser humano que, visto sob uma perspectiva integrada, não pode ser considerado um recurso; antes, como um gerador de recursos.

Se considerarmos que paradigmas estão presentes na formulação de perguntas, assim como na busca de respostas, parece sensato argumentarmos que as solu- 
ções para as disfunções do modelo de desenvolvimento adotado sejam buscadas em um contexto mais amplo do que aquele em que foram geradas. Isso significa rever a validade de uma visão de mundo dominante que privilegia abordagens excludentes, fragmentadas e reducionistas, perante uma realidade que se mostra integrada e interdependente (Vergara e Branco, 1993). Nesse sentido, mostram ter enorme valor as contribuições que vêm surgindo nas fronteiras da Ciência. Se tomado o campo das Ciências Sociais, e nele o da Administração em particular, essas contribuições apontam para o inadiável questionamento e redefinição do papel das organizações na sociedade, assim como das práticas de gestão. Tal revisão deixa antever a superação de dicotomias, hoje inaceitáveis, que têm levado a escolhas entre competição ou cooperação, dominação ou parceria, quantidade ou qualidade, expansão ou conservação, enfim, dicotomias que privilegiam o "ou" em detrimento do "e".

Várias iniciativas que hoje tomam forma no contexto das empresas sugerem que muitas das dicotomias que sempre caracterizaram a realidade dos negócios começam a dar lugar a abordagens mais integradas e interdependentes. Discuti-las pode ser revelador.

\section{O PAPEL DAS EMPRESAS DIANTE DA INADIÁVEL NECESSIDADE DE CONCILIAÇÃO ENTRE COMPETITIVIDADE E HUMANIZAÇÃO}

As tradições orientais têm sido invocadas como fonte de reflexão e inspiração por muitos de nós, ocidentais, frustrados com as limitações de nossa visão de mundo que insiste em excluir, fragmentar e reduzir. Numa dessas incursões às heranças milenares do Oriente, passamos a nos referir às crises como um fenômeno que poderia ser visto tanto como fonte de perigo quanto de oportunidade. Isso porque, na língua chinesa, a palavra crise (wei-jin) traz em si esse duplo significado. Parte dessa lição parece estar sendo muito bem assimilada no mundo dos negócios: ante o perigo do excesso de concorrentes, a oportunidade de se diferenciar pela qualidade; diante do perigo da guerra de preços, a oportunidade de atender a consumidores dispostos a pagar menos; ante o perigo da entrada de um competidor mais poderoso, a oportunidade de aliar-se a ele; diante do perigo da escassez de recursos, a oportunidade de fazer mais com menos.

Entretanto, essa competência para identificar oportunidades nas quais muitos só percebem perigo, não se tem revelado diante da necessidade de identificaremse as verdadeiras crises que hoje precisam ser enfrentadas. Esse descompasso pode ser observado na escassez de soluções para a crise ambiental de nosso planeta, na inabilidade para superação das desigualdades entre países, comunidades e indivíduos, assim como na insistência em uma visão de mundo que não privilegia os valores e significados humanos (Harman, 1995). Como um dos agentes da sociedade contemporânea, as organizações empresariais não são a única instituição a demonstrar essa incapacidade. Acontece que seus equívocos ou omissões hoje se traduzem em conseqüências insustentáveis. É urgente colocar as competências e recursos até hoje utilizados pelas organizações na superação dos desafios mercadológicos a serviço de um desenvolvimento efetivamente sustentável.

Ao discutir o atual papel das empresas, Korten (1997) assinala que, das 100 maiores economias mundiais, 51 são de corporações transnacionais e 49 de países. Em termos econômicos, a Mitsubishi é maior do que a Indonésia, o quarto país mais populoso do mundo. Também é ilustrativo o fato de que a soma da receita das duzentas maiores corporações equivale a quase $30 \%$ do produto bruto mundial.

Ocorre que esse inquestionável poder econômico em parte vem sendo obtido a um custo social inaceitável. Isso porque as múltiplas externalidades associadas à atividade empresarial, sob a forma de degradação da natureza, condições de trabalho impróprias e produtos inadequados às necessidades humanas, vêm sendo tratadas por meio da privatização dos ganhos e da socialização dos custos. Caso consideremos a crescente competitividade que hoje caracteriza o mundo dos negócios, são preocupantes as conseqüências da manutenção dessa prática, assim como incoerentes as situações que se criam. Basta que tomemos o exemplo citado por Ryland (1998), segundo o qual grandes empresas norte-americanas do setor de saúde investem alguns milhões de dólares em ações de empresas de cigarro.

Analisando-se os desafios que temos a enfrentar como sociedade e o poder hoje representado pelas empresas, podemos argumentar quanto ao seu necessário envolvimento com a eliminação das externalidades tidas como inerentes às suas atividades. Nesse sentido, despontam empresas assumindo compromissos com a redução de impactos ambientais, com o apoio a grupos socialmente excluídos, com a erradicação das múltiplas causas de pobreza, tais como a ausência de educação. Essas ações não só acenam com a conciliação entre competitividade e humanização das empresas como parecem revelar indícios de que um novo paradigma esteja emergindo no mundo dos negócios. Investigar essa possibilidade é, por si só, instigante.

As empresas que vêm implementando ações humanizadas sob diversas formas revelam alguma sintonia com o argumento de Harman (1996) de que a empresa moderna é extremamente adaptável. Percebidas como manifestação de sua responsabilidade social (Esteves, 
2000), as ações implementadas por essas empresas também reforçam a percepção de Abell (1998) quanto à obsolescência da premissa de que o único objetivo de um negócio é o lucro. Trata-se de uma premissa que já não se mostra suficiente para enfrentar os desafios que se apresentam. Ao se manterem submetidas a ela, as empresas estarão materializando a metáfora lembrada por Aktouf (1996), segunda a qual se corre o risco de estar serrando o próprio galho no qual se está sentado.

A história da vida na Terra dá lições surpreendentes. Ela tem revelado, como ensinam Margulis e Segan (citados por Capra, 1997, p. 185) que "a vida não se apossa do globo pelo combate, mas, sim, pela formação de redes". Práticas destrutivas não encontram a vida eterna. Triunfam a cooperação e a criatividade. Desde que as primeiras células nucleadas foram criadas, arranjos de cooperação e de co-evolução foram o procedimento da evolução (Capra, 1997).

Talvez porque conheçam a teoria, talvez por intuição, sensibilidade ou inteligência, o fato é que várias empresas estão se tornando permeáveis à prática de ações que levam em conta a co-evolução de sua rede interna e a de seu ambiente e que aqui são designadas empresas humanizadas. Ao serem apresentados exemplos de empresas desse tipo, é importante que se leve em conta que não estamos considerando a totalidade de suas operações, mas, sim, um determinado projeto ou conjunto de ações. Da mesma forma, sugerimos que não sejam estabelecidas correlações entre as ações tidas como humanizadas por parte dessas empresas e seus respectivos desempenhos econômico-financeiros, visto que inúmeras outras variáveis impactam esse desempenho e aqui não estão sendo consideradas.

\section{AÇÕES DE EMPRESAS HUMANIZADAS}

Como em outros temas aos quais se tem dedicado a literatura de negócios, também no campo da chamada cidadania corporativa, a presença freqüente de algumas empresas na mídia vem contribuindo para que se tornem verdadeiros ícones do que aqui estamos considerando uma organização humanizada. Num contexto internacional, são nomes já consagrados o da fabricante inglesa de cosméticos Body Shop, das norte-americanas Ben \& Jerry's, Levi Strauss e Toys "R" Us, respectivamente, uma rede de sorveterias, uma fabricante de roupas e uma rede varejista de brinquedos (Reder, 1995).

No Brasil, apesar de ser mais recente a cobertura da mídia, já se verificam algumas unanimidades no que se refere a exemplos de empresas humanizadas. Dentre elas, destacam-se a C\&A, Natura, Banco Itaú, CocaCola e outras. Menos citadas, mas desenvolvendo ações igualmente relevantes, também existem no Brasil mé- dias e pequenas empresas que não se intimidam pela escassez de recursos quando o assunto é atuar por uma causa com a qual se identificam. Algumas delas serão aqui mencionadas.

\section{É urgente colocar as \\ competências e recursos}

até hoje utilizados pelas

organizações na superação

dos desafios mercadológicos a

serviço de um desenvolvimento

efetivamente sustentável.

No caso da C\&A, uma das maiores redes de varejo de roupas do mundo, o apoio às comunidades próximas às lojas instaladas no Brasil tem sido conduzido pelo Instituto C\&A. Como foco de suas ações, o Instituto C\&A voltou-se para a educação de crianças e adolescentes de baixa renda e o apoio às regiões atingidas por calamidades. Para esse fim, tem investido, anualmente, 4 milhões de dólares em cerca de 350 projetos (Vassallo, 1999). Dentre esses projetos, destacam-se os de capacitação de educadores, apoio a diretores de escolas públicas no planejamento e administração e formação de centros comunitários para apoio a crianças e adolescentes. Além de recursos financeiros, o instituto disponibiliza para esses projetos o tempo dos empregados da C\&A que atuam como voluntários. No relacionamento com fornecedores também estão presentes os compromissos sociais da empresa. Nesse sentido, faz parte das responsabilidades dos diretores e gerentes das unidades instaladas no Brasil a fiscalização das condições de trabalho oferecidas pelos fornecedores da empresa.

Entre as empresas do setor financeiro, historicamente vistas como pouco sensíveis a qualquer assunto que não esteja diretamente associado à maximização do lucro, já podem ser mencionadas várias iniciativas que apontam para o que Kanitz (1998) identifica como a transformação do capitalismo de resultados para o capitalismo de benefícios. O Bradesco, por intermédio da sua fundação, já é uma referência obrigatória quando se fala do apoio empresarial à educação de crianças e jovens. No caso do Itaú, ações dessa natureza têm sido conduzidas 
pelo Instituto Itaú Cultural, o qual tem sido internacionalmente reconhecido pelo conjunto de seu trabalho na área social. Tanto o Bradesco quanto o Itaú fazem parte de um grupo de empresas que apóia um canal de TV por assinatura inteiramente dedicado à educação: o canal Futura.

Um outro representante do setor financeiro, o BankBoston, também tem protagonizado ações significativas. Com uma de suas unidades operando em uma região da cidade de São Paulo caracterizada pela insegurança e violência urbana, o banco adotou um comportamento proativo. Em parceria com o Sindicato dos Bancários de São Paulo, criou o Projeto Travessia, o qual busca levar crianças e jovens que vivem nas ruas de volta a seus lares e dar a elas o acesso à educação (Vassalo, 1998). Com um investimento anual em torno de 1,5 milhão de dólares, o projeto hoje conta com a participação de outras organizações como o Bradesco, o Banco Fibra e a Fundação Abrinq, esta última ligada às indústrias de brinquedos.

As deficiências no campo da educação também foram o alvo escolhido pela Coca-Cola para expressar sua cidadania. Por meio do Programa Coca-Cola de Valorização do Jovem, a empresa procura contribuir no combate à evasão escolar. Já aceito como um dos integrantes oficiais do projeto Acorda Brasil do Ministério da Educação, esse programa baseia-se no monitoramento escolar feito por jovens entre 15 e 17 anos com seus colegas da $6^{\mathrm{a}}$ a $8^{\mathrm{a}}$ séries, durante o ano letivo (Riani, 1999).

Valendo-se da enorme capilaridade da sua rede de revendedoras, a Avon tem na mulher não só seu público-alvo mas também o foco de suas ações sociais. Em cada país onde atua, a empresa prepara essas revendedoras não só para vender seus produtos, mas também para transmitir informações que promovam a qualidade de vida da mulher. No Brasil, as $500 \mathrm{mil}$ revendedoras da empresa são treinadas para oferecer dicas de saúde às suas clientes.

Também do setor de cosméticos, a brasileira Natura vem dedicando anualmente cerca de 3,5\% do seu lucro líquido aos projetos sociais (D’Ambrosio, 1998). Contando com uma gerência de Ação Social, a Natura concentra seus recursos na área de educação. Uma de suas iniciativas, o programa Crer para Ver, mobiliza o voluntariado de seus profissionais internos e das $20 \mathrm{mil}$ consultoras independentes que comercializam os produtos Natura. Esses voluntários são convidados a desenvolver e comercializar cartões, embalagens e camisetas, cujos recursos arrecadados são destinados ao financiamento de projetos de melhoria do ensino público. Nos três anos de existência do programa, 3,7 milhões de reais foram destinados a 65 projetos que beneficiaram mais de 150 mil crianças.
Certificada como Empresa Amiga da Criança pela Fundação Abrinq, a qual concede um selo para as empresas que combatem o trabalho infantil, a Natura inseriu uma cláusula de responsabilidade social nos contratos que firma com seus fornecedores. Em um caso recente, verificou-se que um fornecedor empregava adolescentes sem registro, violando a referida cláusula. O desligamento do fornecedor seria uma reação esperada, mas com custos sociais visíveis. A decisão consistiu em desenvolver um trabalho com a empresa fornecedora para regularizar a situação (D’Ambrosio, 1998).

Para a Cerâmica Portobello, empresa catarinense do setor de pisos e revestimentos, a melhoria da qualidade de vida dos seus funcionários e a valorização da cidade onde está situada têm sido o foco dos investimentos na área social. Envolvendo a prefeitura local e a Caixa Econômica Federal, o projeto Alamandas, desenvolvido pela empresa, possibilita o acesso à casa própria para muitos de seus empregados. A doação do terreno é feita pela empresa, cabendo à prefeitura a realização das obras de infra-estrutura. Os recursos para a construção são viabilizados pelo crédito associativo oferecido pela Caixa Econômica, que proporciona aos novos proprietários prestações mensais menores do que o aluguel que até então pagavam (Botelho e Boechat, 1998).

Para três fabricantes de calçados do Rio Grande do Sul, a própria embalagem dos produtos que distribuem foi vista como um veículo para mensagens que podem ser úteis quando o assunto é a melhoria das condições de vida. Focalizando a prevenção do câncer de mama, o incentivo ao acesso das crianças à escola, a divulgação de fotos de crianças desaparecidas, a prática de hábitos de higiene bucal pelas crianças e a preservação do meio ambiente, as mensagens divulgadas nas embalagens da Bibi, da Richter e da Bottero representam, segundo um de seus executivos, "pequenas ações que podem ajudar o comportamento das pessoas", porque "não podemos esperar que o governo faça tudo sozinho" (Caporal, 1998, p. A-9).

Para realizar ações sociais, mesmo sem os recursos de que dispõem as fundações e institutos criados pela grandes corporações, as pequenas e médias empresas vêem, nas parcerias formadas entre elas e com associações setoriais, uma alternativa bastante efetiva. Para estimular essas iniciativas, o Serviço de Apoio às Micro e Pequenas Empresas (Sebrae) e o Serviço Nacional de Aprendizagem Comercial (Senac) contam com projetos específicos, como é o caso do Programa de Projetos de Gestão de Desenvolvimento Socio-Econômico do Sebrae-SP, voltado para a formação de agentes sociais de acordo com vocações regionais que possam contribuir para o desenvolvimento das comunidades locais (Projeto Aprendiz, 1999). 
Contando com o apoio do Senac, cerca de 100 empresas de pequeno porte de São Paulo estão envolvidas no Programa de Educação para o Trabalho. Por meio desse programa, 4 mil adolescentes carentes entre $14 \mathrm{e}$ 18 anos já receberam, desde 1997, algum tipo de formação técnica. Cabe às empresas participantes o apoio às instituições sociais às quais esses adolescentes estão ligados, a oferta de estágios e até mesmo a contratação, como se deu na Segatto Móveis, uma empresa moveleira de 41 funcionários (Projeto Aprendiz, 1999).

Além dos projetos que recebem apoio institucional de grandes, médias e pequenas empresas, também começam a ser freqüentes aqueles que contam com o auxílio de empresários e executivos que, individualmente, colocam algum tipo de recurso a serviço da construção de um mundo melhor. Muitas vezes, esses recursos se traduzem na dedicação de uma parcela de tempo na aplicação de conhecimentos de gestão a uma causa com que esses indivíduos se identificam. Esse é o caso de João Roncati, gerente financeiro dos Laboratórios Biosintética, que ajuda no planejamento estratégico da organização Doutores da Alegria, que oferece assistência a crianças hospitalizadas (Projeto Aprendiz, 1999).

Para facilitar a aproximação entre as instituições sociais e os profissionais que, como o executivo João Roncati, estejam dispostos a disponibilizar seus conhecimentos por meio de um trabalho voluntário, encontra-se disponível um site na Internet (www.voluntarios.com.br) que cadastra esses profissionais e indica as necessidades de diversas instituições. Mantido pela Kanitz Associados, o site conta com um número expressivo de adesões.

Quando se analisam as iniciativas das empresas aqui citadas e as de tantas outras que começam a exemplificar o conceito de organizações humanizadas, podemos identificar algumas estratégias que merecem ser seguidas. A principal delas diz respeito à escolha de um foco, ou seja, a identificação de uma causa prioritária para a qual serão canalizados os recursos e esforços. No caso de muitas das empresas aqui citadas, esse foco foi a educação.

Também nos ensinam as experiências bem-sucedidas que é fundamental o envolvimento dos empregados em torno da causa escolhida. Todos precisam reconhecer, nas ações de que participam, uma real possibilidade de fazer diferença para as pessoas e instituições beneficiadas.

Dado que o apoio a uma determinada causa social pode exigir competências de que a empresa não dispõe, o estabelecimento de parcerias com profissionais e instituições especializadas é uma garantia para a aplicação mais adequada dos recursos. Além desses cuidados, não se deve deixar de lado a ortodoxia dos bons manuais de Administração, que prescrevem os meios eficientes para atingirmos os fins estabelecidos. Julgando-se a natureza dos fins para os quais se voltam as empresas humanizadas, é de se esperar que a Administração tenha muito a contribuir para alcançá-los.

\section{Parece acertado afirmar que,} no século que se inicia, as empresas serão julgadas por seus compromissos éticos, pelo foco nas pessoas (empregados, clientes, fornecedores, concorrentes e cidadãos em geral) e pelas relações responsáveis com o ambiente natural.

\section{CONCLUSÃO}

Este artigo teve por objetivo discutir o conceito de organização humanizada, além de apontar e justificar a necessidade e a possibilidade de sua viabilização. Considerando a relação de interdependência entre empresa e sociedade, bem como o poder econômico e a competência técnica que norteiam o ambiente de negócios, é fácil perceber a relevância do que aqui foi apresentado.

Parece acertado afirmar que, no século que se inicia, as empresas serão julgadas por seus compromissos éticos, pelo foco nas pessoas (empregados, clientes, fornecedores, concorrentes e cidadãos em geral) e pelas relações responsáveis com o ambiente natural. O paradigma que as têm sustentado apresenta anomalias e novas ações se impõem.

Ações humanizadas serão vistas como fonte de diferenciação em um ambiente de negócios, o qual não dá nenhuma indicação de que deixará de ser competitivo. Parece incongruente, já que tais ações, em princípio, representam aumento de custos? Não. Até onde se pode inferir pela vivência e observação da prática cotidiana, bem como pelas notícias que são divulgadas em âmbito mundial, consumidores estarão dispos- 
tos a, cada vez mais, incorporarem em suas decisões de compra os compromissos éticos que as empresas parecem reclamar de seus fornecedores. $\mathrm{Na}$ mesma direção, profissionais talentosos estarão, mais e mais, sentindo-se atraídos por empresas comprometidas com o crescimento das pessoas e com causas sociais e ecológicas. Se clientes fiéis e empregados talentosos compõem, sem dúvida, um grande diferencial competitivo, empresas humanizadas serão, cada vez mais, necessárias e possíveis.

REFERÊNCIAS BIBLIOGRÁFICAS

ABELL, Derek. Um horizonte além da rentabilidade. Gazeta Mercantil, São Paulo, 25 ago. 1998. Série 0 Domínio da Globalização, n. 8, p. 19-21.

AKTOUF, Omar. A administração entre a tradição e a renovação. São Paulo : Atlas, 1996.

BOHM, David. A totalidade e a ordem implicada. São Paulo : Cultrix, 1992.

BOTELHO, Diógenes, BOECHAT, Yan. Empresa social. Empreendedor, São Paulo, ano 4, n. 47, p. 10-18, set. 1998.

CAPORAL, Angela. Caixas de papel ganham uma "função social”. Gazeta Mercantil, São Paulo, 3 ago. 1998. p. A-9.

CAPRA, Fritjof. O tao da Física. São Paulo : Cultrix, 1975.

CAPRA, Fritjof. O ponto de mutação. São Paulo : Cultrix, 1982.

CAPRA, Fritjof. A teia da vida. São Paulo : Cultrix, 1997.

CHANLAT, Jean-François. L'individu dans l'organization. Quebec : Eska, 1990.

COHEN, David. Mais esta agora: será que eu tenho que saber Física Quântica? Exame, São Paulo, ano 32, n. 23 , p. 106-112, 4 nov. 1998

D’AMBROSIO, Daniela. Ação social nos negócios. Gazeta Mercantil, São Paulo, 27 nov. 1998. Relatório Terceiro Setor, p. 1.

ESTEVES, Sérgio A. P. (Org.). O dragão e a borboleta: sustentabilidade e responsabilidade social das empresas. São Paulo : Axis Mundi/AMCE, 2000.

FORRESTER, Viviane. O horror econômico. São Paulo : Universidade Estadual Paulista, 1997.

FREIRE, Paulo. Pedagogia do oprimido. Rio de Janeiro : Paz e Terra, 1974.

HARMAN, Willis W. The challenge of creating a new social order. In: INTERNATIONAL CONFERENCE ON ORGANIZATIONAL DEVELOPMENT, 1995, Puerto Vallarta, México. Anais... Puerto Vallarta, Mexico : Institute of Noetic Sciences, 1995.
HARMAN, Willis W. 0 mundo dos negócios no século XXI: um pano de fundo para o diálogo. In: RENESCH, John. Novas tradições nos negócios: valores nobres e liderança no século XXI. São Paulo : Cultrix, 1996.

HERN, Matt (Org.). Deschooling our lives. Gabriola Island New Society Publishers, 1996.

KANITZ, Stephen. Capitalismo beneficente. Veja, São Paulo, p. 21, 27 maio 1998 .

KORTEN, David C. A market-based approach to corporate responsibility: perspectives on business and global change World Business Academy, San Francisco, v. 11, n. 2, p. 4555, June 1997.

KUHN, Thomas S. A estrutura das revoluções científicas. São Paulo : Perspectiva, 1982

LEAL, Guilherme Peirão. Empresa ética não é sonho. Exame, São Paulo, ano 32, n. 22, p. 142, 21 out. 1998.

LYNN, Jonathan. Nobel de Economia vai para indiano estudioso da prosperidade social. Gazeta Mercantil, São Paulo, 15 out. 1998. p. A-12.

MACHADO, Luiz. Descubra e use a sua inteligência emocional. Rio de Janeiro : L. Machado, 1997.

MATURANA, Humberto, VARELA, Francisco. De máquinas y seres vivos. Santiago : Editorial Universitaria, 1972.

MORIN, Edgar. Ciência com consciência. Rio de Janeiro Bertrand Brasil, 1996.

ONU. Human Development Report 1998. Disponivel na Internet <http://www.undp.org >.

ONU. Human Development Report 2000. Disponível na Internet <http://www.undp.org>.

ORR, David W. Earth in mind: on education, environment, and the human prospect. Washington : Island Press, 1994.

PRIGOGINE, Ilya, STENGERS, Isabelle. Order out of chaos New York : Bantam, 1984.

PRIGOGINE, Ilya. O fim das certezas. São Paulo : Fundação Unesp, 1996.
PROJETO APRENDIZ. Pequenas realizam trabalho social. 1999. Disponível na Internet <http:// www.aprendiz.com.br>.

RAY, Michael. Qual é o novo paradigma nos negócios? In RAY, Michael, RINZLER, Alan (Orgs.). O novo paradigma nos negócios: estratégias emergentes para liderança e mudança organizacional. São Paulo : Cultrix, 1997.

REDER, Alan. 75 best business practices for socially responsible companies. New York: Tarcher/Putnam Book, 1995.

RIANI, Mônica. Evasão escolar no Rio será combatida com apoio empresarial. Gazeta Mercantil, Rio de Janeiro, 10 mar. 1999. Caderno Gazeta do Rio, p. 1.

RYLAND, Elisabeth K. "Greening" business education: teaching the paradigm. Journal of Management Education, London, v. 22, n. 3, p. 320-343, June 1998.

SCHUMACHER, E. F. O negócio é ser pequeno: um estudo de Economia que leva em conta as pessoas. Rio de Janeiro : Zahar Editores, 1983.

SORMAN, Guy. Os verdadeiros pensadores de nosso tempo. Rio de Janeiro : Imago, 1989.

TOFFLER, Alvin. O choque do futuro. São Paulo : Artenova, 1981.

VASSALLO, Cláudia. Fazer o bem compensa? Exame, São Paulo, ano 31, n. 9, p. 23-30, 22 abr. 1998.

VASSALLO, Cláudia. Um caso exemplar. Exame, São PauIo, ano 32, n. 28, p. 69-79, 13 jan. 1999.

VERGARA, Sylvia Constant, BRANCO, Paulo Durval. Em busca da visão de totalidade. RAE - Revista de Administração de Empresas, São Paulo, v. 33, n. 6, p. 20-31, nov./ dez. 1993.

WILBER, Ken. O espectro da consciência. São Paulo : Cultrix, 1977.

WILBER, Ken (Org.). O paradigma holográfico e outros paradoxos. São Paulo : Cultrix, 1991. 